\title{
KONSONAN DALAM BAHASA KOLONCUCU
}

\section{CONSONS IN THE COLONCUCU LANGUAGE}

\author{
Fida Febriningsih \\ Kantor Bahasa Maluku Utara \\ Jalan Wijaya Kusuma Nomor 81, Kota Ternate \\ Ponsel: 081355019689 \\ Pos-el: 0202fida@gmail.com
}

\begin{abstract}
Abstrak
Bahasa Koloncucu adalah salah satu bahasa daerah di Maluku Utara yang tergolong dalam kategori bahasa yang punah (moribund languages), karena memiliki jumlah penutur yang sangat sedikit. Dalam hitungan beberapa decade, bahasa ini akan benarbenar hilang bersama dengan penuturnya. Data ilmiah tentang bahasa inipun belum banyak dilakukan. Tulisan ini bertujuan untuk mendeskripsikan bentuk dan klasifikasi konsonan dalam bahasa Koloncucu, sebagai salah satu upaya pelestarian bahasa daerah. Penelitian ini menggunakan metode deskripsi dengan tiga tahapan, yaitu tahap penyediaan data, tahap analisis data, dan tahap penyajian hasil analisis data. Analisis data dilakukan setelah proses klasifikasi data yang kemudian diterapkan menggunakan metode agih dengan teknik bagi unsur langsung. Hasil tulisan ini adalah bentuk dan klasifikasi konsonan dalam bahasa Koloncucu, yaitu: konsonan hambat letup (Stops, Plosives), konsonan nasal (Nasals), konsonan sampingan (Laterals), konsonan geseran atau frikatif (Fricatives, Fristions), konsonan getar (Trills, Vibrants), dan semi vokal. Sedangkan konsonan sentuhan (Tap), konsonan sentuhan kuat (Flap), dan konsonan paduan (Affricates) tidak ditemukan dalam bahasa Koloncucu.
\end{abstract}

Kata kunci: bahasa daerah, Koloncucu, konsonan, bentuk, klasifikasi

\begin{abstract}
Koloncucu language is one of the regional languages in North Maluku belonging to the category of extinct languages (moribund languages), because it has a very small number of speakers. Within a few decades, this language will completely disappear with the speaker. Scientific data on this language has not been done. This paper aims to describe the form and classification of consonants in Koloncucu language, as one of the efforts to preserve local languages. This research uses descriptive method with three stages, namely data supply stage, data analysis phase, and presentation stage of data analysis. Data analysis is done after the data classification process is then applied using the agih method with the technique for the direct element. The results of this paper are the form and classification of consonants in Koloncucu language, namely: the consonant of the larup (Stops, Plosives), nasal consonants (Nasals), side consonants (Laterals), fricative, fristions consonants, vibrating consonants (Trills, Vibrants), and semi vocals. While the touch consonants (Tap), strong touch consonants (Flap), and consonant alloys (Affricates) are not found in Koloncucu.
\end{abstract}

Keywords: regional language, Koloncucu, konsonan, form, classification 


\section{Pendahuluan}

\subsection{Latar Belakang Masalah}

Bahasa daerah adalah kekayaan bangsa, refleksi dari perkembangan pemikiran dan kepribadian setiap suku bangsa. Begitu banyak sastra lisan yang diramu dalam bahasa daerah yang indah dan memiliki nilai-nilai positif tentang kehidupan. Bahasa daerah diturunkan oleh nenek moyang dari satu generasi ke generasi lain melalui proses yang panjang dan berkesinambungan. Dalam perkembangannya, tidak jarang bahasa daerah memiliki perubahan, baik dari sistem bahasa maupun sikap penuturnya. Bahasa daerah penting untuk dilestarikan, karena kepunahan bahasa berarti juga kematian kekayaan (pikiran dan kepribadian) bagi setiap kelompok etnis.

Bahasa yang terdapat di Provinsi Maluku Utara terbagi menjadi 31 bahasa, yaitu bahasa Galela, Tobelo, Loloda, Gorap, Laba, Tugutil, Ibu, Modole, Tobaru, Gamkonora, Wayoli, Kao, Sahu, Pagu, Ternate, Melayu Ternate, Tidore, Buli, Maba, Patani, Sawai, Makian Luar, Makian Dalam, Bacan, Gane, Gebe, Taliabu, Sula, Koloncucu, Kadai, dan Mangole. Salah satu bahasa yang hampir punah di Maluku Utara adalah bahasa Koloncucu (Perda Maluku Utara, 2011). Penutur bahasa Koloncucu terdapat di Kelurahan Toboleu dan Kelurahan Kasturian. Jumlah penutur bahasa Koloncucu diperkirakan berjumlah empat orang (Fokaaya, dkk, 2014), dua sebagai penutur aktif dan dua lainnya sebagai penutur pasif.

Tipologi Michel Krauss (1992: 410) mengelompokkan bahasa-bahasa di dunia ke dalam: (1) bahasa-bahasa yang punah (moribund languages), (2) bahasabahasa yang terancam punah (endangered languages), dan (3) bahasabahasa yang masih aman (safe languages). Bahasa Koloncucu sudah tergolong dalam kategori bahasa-bahasa yang punah (moribund language) karena tidak lagi secara aktif digunakan dan tidak lagi dikuasai oleh penutur yang berusia di bawah 50 tahun. Bahasa Koloncucu hanya digunakan oleh sejumlah kecil penutur yang berusia di atas 50 tahun. Dalam hitungan satu dekade, bahasa ini akan punah, dalam artian tidak digunakan lagi. Salah satu penyebab punahnya bahasa Koloncucu adalah karena para orang tua tidak lagi mengajarkan bahasa tersebut kepada anak-anaknya, dan tidak lagi secara aktif menggunakannya di rumah dan berbagai ranah komunikasi lainnya. Pengaruh Kesultanan Ternate di masa lalu, dengan wilayah kekuasaan yang luas juga turut memberi tekanan kebahasaan terhadap bahasa-bahasa minoritas, salah satunya bahasa Koloncucu. Kelurahan Toboleu dan Kasturian yang dulunya merupakan wilayah pakai bahasa Koloncucu, kini telah tergantikan oleh bahasa Ternate.

Berdasarkan penelusuran kepustakaan, bahasa ini belum banyak mendapat perhatian sebagai objek kajian ilmiah. Penelitian tentang bahasa Koloncucu baru dilakukan oleh tim peneliti Kantor Bahasa Maluku Utara pada tahun 2014. Hasil penelitian berupa draf kamus Bahasa Indonesia-Bahasa Koloncucu. Minimnya perhatian terhadap bahasa Koloncucu, sehingga penulis menganggap tulisan ini sangat penting sebagai salah satu bentuk dukungan terhadap pelestarian bahasa daerah, khusunya bahasa Koloncucu. Masalah yang dibahas dalam tulisan ini ialah (1) bagaimana deskripsi konsonan dalam bahasa Koloncucu dan (2) bagaimanakah konsonan diklasifikasi dalam bahasa Koloncucu? Sekaitan dengan masalah, tujuan kajian ini adalah mendeskripsikan bentuk dan mengklasifikasikan konsonan dalam bahasa Koloncucu. 


\section{Teori dan Metode}

\subsection{Kerangka Teori}

Menurut Pateda (2001:92) bahwa bahasa daerah adalah bahasa yang lazim digunakan dalam satu daerah sebagai alat komunikasi dalam segala hal. Setiap bahasa daerah memiliki sistem bunyi dan struktur bahasa tersendiri (gramatika/tata bahasa). Ilmu mengenai unsur bunyi dalam linguistik disebut fonologi. Trubetzkoy (dalam Kenjono, 2005:45) menjelaskan bahwa fonologi merupakan studi bunyi yang berkenaan dengan sistem bahasa, organisasi bahasa, serta studi fungsi linguistis bahasa. Kaitannya mengenai studi fungsi linguistis bahasa, bunyi-bunyi bahasa tersebut mempunyai fungsi sebagai pembeda arti. Hal ini sesuai dengan pernyataan Verhaar (2010:10) bahwa fonologi itu bertugas untuk membicarakan bunyi bahasa menurut fungsi, terutama sebagai pembeda arti. Bunyi yang mempunyai fungsi tersebut disebut fonem.

Secara umum, bunyi bahasa dibedakan atas vokal, konsonan, dan semi-vokal. Bunyi disebut konsonan bila terjadinya dibentuk dengan menghambat arus udarapada sebagian alat bicara, jadi ada artikulasi. Proses hambatan atau artikulasi ini dapat disertai dengan bergetarnya pita suara, jika hal ini yang terjadi, maka yang terbentuk adalah bunyi konsonan bersuara. Jika artikulasi itu tidak disertai bergetarnya pita suara, glottis dalam keadaan terbuka, maka bunyi yang dihasilkan adalah konsonan tak bersuara (Marsono, 1986:17).

Berbeda dengan klasifikasi vokal, dalam klasifikasi konsonan tidak diperlukan prinsip-prinsip bunyi kardinal. Karena secara fisiologis antara konsonan satu dengan yang lain lebih mudah dibedakan daripada vokal-vokal. Secara praktis biasanya konsonan dibedakan menurut: a. cara hambat (cara artikulasi); b. tempat hambatan (tempat artikulasi); c. hubungan posisional antara penghambat- penghambatnya atau hubungan antara artikulator aktif dengan pasif (struktur); dan d. bergetarnya pita suara. (Marsono, 1986:60). Klasifikasi konsonan berdasarkan empat kriteria tersebut diuraikan menjadi: konsonan hambat letup (Stops, Plosives), konsonan nasal (Nasals), konsonan paduan (Affricates), konsonan sampingan (Laterals), konsonan geseran atau frikatif (Fricatives, Fristions), konsonan getar (Trills, Vibrants), konsonan sentuhan (Tap), konsonan sentuhan kuat (Flap), dan semi vokal.

Sesuai dengan artikulasinya, konsonan dalam bahasa Indonesia dapat dikategorikan berdasarkan tiga factor: 1 . keadaan pita suara, 2. daerah artikulasi, dan 3. cara artikulasinya. Berdasarkan kedaan pita suara, konsonan dapat bersuara dan tak bersuara; berdasarkan daerah artikulasinyam konsonan dapat bersifat bilabial, labiodental, alveolar, palatal, velar, atau glotal; dan berdasarkan cara artikulasinya, konsonan dapat berupa hambat, frikatif, nasal, getar atau lateral. Di samping itu, adalagi yang berwujud semi vokal (Alwi, dkk., 1998:65)

\subsection{Metode}

Penelitian ini menggunakan metode deskripsi dengan tiga tahapan, yaitu tahap penyediaan data, tahap analisis data, dan tahap penyajian hasil analisis data (Sudaryanto, 1993: 9). Tahap pengumpulan data diawali dengan menyusun instrumen penelitian dalam bentuk kuosioner, kemudian menggunakan informan sebagai sumber data lisan yang hasilnya dicatat dan direkam. Setelah data terkumpul, selanjutnya dilakukan analisis data dengan metode agih. Metode Agih adalah metode yang alat penentunya merupakan bagian dari bahasa itu sendiri, misalnya kata, frasa, klausa, dan sebagainya (Sudaryanto, 1993:15--16). Pelaksanaan 
metode agih ini dijabarkan dalam suatu teknik dasar dan teknik lanjutan. Teknik dasar yang dimaksud yaitu teknik bagi unsur langsung (BUL). Pada tahap penyajian hasil analisis data menggunakan teknik informal yang disajikan dalam bentuk deskripsi bahasa atau menggunakan kata-kata biasa.

\section{Pembahasan}

\subsection{Konsonan dalam Bahasa Koloncucu}

Berkaitan dengan tulisan ini, konsonan dalam bahasa koloncucu dibagi dalam beberapa bentuk yaitu: konsonan hambat letup (Stops, Plosives), konsonan nasal (Nasals), konsonan paduan (Affricates), konsonan sampingan (Laterals), konsonan geseran atau frikatif (Fricatives, Fristions), konsonan getar (Trills, Vibrants), konsonan sentuhan (Tap), konsonan sentuhan kuat (Flap), dan semi vokal. Berikut ini penjelasannya.

\subsubsection{Konsonan hambat letup (Stops, Plosives)}

Konsonan hambat letup ialah konsonan yang terjadi dengan hambatan penuh arus udara, kemudian hambatan itu dilepaskan secara tiba tiba . Jadi, strukturnya rapat, kemudian dilepaskan secara tiba-tiba. Struktur rapat yang pertama disebut hambatan, sedangkan struktur pelepasan yang kedua disebut letupan. Menurut tempat hambatannya (artikulasinya) konsonan ini dapat diperinci lagi menjadi:

\subsubsection{Konsonan hambat letup bilabial}

Konsonan hambat letup bilabial terjadi bila penghambat artikulator aktifnya adalah bibir bawah dan artikulator pasifnya adalah bibir atas, seperti bunyi [p] dan [b], perbedaan diantara keduanya ialah [p] sebagai konsonan keras tak bersuara, sedangkan [b] adalah lunak bersuara. Distribusi bunyi [p] dan [b] dalam bahasa Koloncucu:

$\begin{array}{llll}\text { Konsonan } & \text { awal } & \text { tengah } & \text { akhir } \\ \text { [p] } & \text { pomea } & \text { mopita } & - \\ & \text { 'bayar' } & \text { 'basah' } & - \\ \text { [b] } & \text { basiako } & \text { labu } & - \\ & \text { 'buang' } & \text { 'besi' } & -\end{array}$

bunyi [p] dalam bahasa Koloncucu yang berdistribusi di awal dan tengah adalah hambat letup, yaitu proses penghambatan arus udara terjadi lebih dahulu baru kemudian diletupkan. Hal yang sama juga untuk [b] yang hanya bisa berdistribusi di awal dan tengah saja. Dalam bunyi [b], beberapa kata diucapkan dengan aspirasi, misalnya

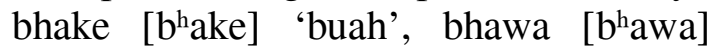
'bawang', sedangkan bunyi [p] dalam bahasa Koloncucu tidak diucapkan dengan aspirasi.

\subsubsection{Konsonan hambat letup apiko- dental}

Konsonan hambat letup apiko-dental terjadi bila penghambat artikulator aktifnya ialah ujung lidah dan artikulator pasifny ialah gigi atas. Distribusi bunyi [t] dan [d] dalam bahasa Koloncucu.

Konsonan awal tengah akhir

$$
\begin{aligned}
& \text { [t] tambu mopita - } \\
& \text { 'gayung' 'basah' } \\
& \text { [d] modaga labu } \\
& \text { 'dagang' 'besi' - }
\end{aligned}
$$

Bunyi [t] dan [d] dalam bahasa Koloncucu tidak bisa berdistribusi sebagai penutup kata, keduanya hanya dapat berdistribusi di awal dan tengah sebagai hambat letup, yaitu proses penghambatan arus udara terjadi lebih dahulu baru kemudian diletupkan. Hal yang sama juga untuk [d] yang hanya bisa berdistribusi di awal dan tengah saja. Dalam bunyi [d], beberapa kata diucapkan dengan aspirasi, misalnya, mondo [mon $\mathrm{d}^{\mathrm{h}} \mathrm{O}$ ] 'genap' dan doloma [d oloma] 'gelap', sedangkan bunyi $[t]$ 
dalam bahasa Koloncucu tidak dapat diucapkan dengan aspirasi.

3.1.1.3 Konsonan hambat letup apikopalatal

Konsonan hambat letup apiko-palatal terjadi bila artikulator aktifnya adalah ujung lidah dan artikulator pasifnya adalah langit-langit keras. Distribusi bunyi [ț dan [ḍ] dalam bahasa Koloncucu.

Konsonan awal tengah akhir

[d] dawo inade -
'ipar' 'dia' -

Bunyi [ț tidak ada dalam bahasa Koloncucu, sedangkan bunyi [d] berdistribusi pada awal dan tengah,dan tidak dapat berdistribusi sebagai penutup kata. Bunyi [d] diucapkan dengan aspirasi, dengan demikian tulisan fonetis untuk dawo [d lawo] 'ipar', inade [inad 'e] 'dia'.

\subsubsection{Konsonan hambat letup medio- palatal}

Konsonan hambat letup medio-palatal terjadi bila artikulator aktifnya adalah tengah lidah, dan artikulator pasifnya adalah langit-langit keras. Distribusi bunyi [c] dan [j] dalam bahasa Koloncucu.

$\begin{array}{llll}\text { Konsonan awal } & \text { tengah akhir } \\ \text { [c] } & \text { cuna } & \text { mewuci } & - \\ & \text { 'gugur' } & \text { 'ingkar' } & - \\ \text { [j] } & \text { jaga } & \text { ijo }, & - \\ & \text { 'jaga' } & \text { 'hijau' } & -\end{array}$

\subsubsection{Konsonan hambat letup dorso-} velar

Terjadi bila artikulator aktifnya adalah pangkal lidah, dan artikulator pasifnya adalah langit-langit lunak. Distribusi bunyi $[\mathrm{k}]$ dan $[\mathrm{g}]$ dalam bahasa Koloncucu.

$\begin{array}{lll}\text { Konsonan awal tengah } & \text { akhir } \\ {[\mathrm{k}]} & \text { kire mokoru } & - \\ & \text { 'kening' 'kuat' } & - \\ {[\mathrm{g}]} & \text { ginta masigi } & -\end{array}$

\section{‘cabai’ ‘mesjid' -}

Bunyi [k] dan [g] dalam bahasa Koloncucu tidak bisa berdistribusi sebagai penutup kata, keduanya hanya dapat berdistribusi di awal dan tengah sebagai hambat letup, yaitu proses penghambatan arus udara terjadi lebih dahulu baru kemudian diletupkan. Hal yang sama juga untuk [d] yang hanya bisa berdistribusi di awal dan tengah saja. Bunyi [k] dan [g] dalam bahasa Koloncucu tidak dapat diucapkan dengan aspirasi.

\subsubsection{Konsonan hamzah}

Bunyi hamzah terjadi dengan menekan rapat yang satu dengan yang lain pada seluruh panjangnya pita suara, langitlangit lunak beserta anak tekaknya dikeataskan sehingga arus udara terhambat untuk beberapa saat. Dengan merapatnya sepasangan pita suara maka glottis alam keadaan tertutup rapat. Secara tiba-tiba kedua selaput pita suara itu dipisahkan, terjadilah letupan udara keluar, dan terdengarlah bunyi [?]

Distribusi bunyi [?] dalam bahasa Koloncucu.

$\begin{array}{lll}\text { Konsonan } & \text { awal } & \text { tengah } \\ \text { [?] } & \text { o'tolu[?tolu] } & \text { to'ori [to?ri] } \\ & \text { akhir } & \\ \text { we'u [we?] } & \\ \text { awal } & \text { tengah } \\ \text { 'tiga' } & \text { 'tahu' } \\ \text { akhir } & \\ \text { 'leher' } & \end{array}$

Dalam bahasa Koloncucu, bunyi [?] tidak hanya dapat berdistribusi di awal dan tengah kata, tetapi juga dapat berfungsi sebagai penutup kata.

\subsubsection{Konsonan Nasal (Nasal)}

Konsonan nasal (sengau) ialah konsonan yang dibentuk dengan menghambat rapat (menutup) jalan udara dari paru-paru melalui rongga mulut, jadi strukturnya 
rapat. Bersama dengan itu, langit-langit lunak beserta anak tekaknya diturunkan, sehingga udara keluar melalui rongga hidung. Menurut tempat hambatannya (artikulasinya) konsonan jenis ini dapat diperinci lagi menjadi sebagai berikut.

\subsubsection{Konsonan nasal bilabial}

Konsonan nasal bilabial terjadi bila penghambat artikulasi aktifnya ialah bibir bawah dan artikulator pasifnya adalah bibir atas. Distribusi bunyi [m] dalam bahasa Koloncucu.

Konsonan awal tengah akhir [m]

$$
\begin{aligned}
& \text { monipi mompu - } \\
& \text { 'tipis' ‘tiup' - }
\end{aligned}
$$

Dalam bahasa Koloncucu, bunyi [m] hanya dapat berdistribusi di awal dan tengah kata sebagai konsonan bersuara, dan tidak dapat berfungsi sebagai penutup kata.

\subsubsection{Konsonan nasal apiko-alveolar}

Konsonan nasal apiko-alveolar terjadi bila penghambat artikulasi aktifnya ialah ujung lidah dan artikulator pasifnya adalah gusi. Distribusi bunyi [n] dalam bahasa Koloncucu.

Konsonan awal tengah akhir [n] nohuo ponahu 'rebus' 'masak' -

Dalam bahasa Koloncucu, bunyi [n] hanya dapat berdistribusi di awal dan tengah kata sebagai konsonan bersuara, dan tidak dapat berfungsi sebagai penutup kata.

\subsubsection{Konsonan nasal medio-palatal}

Konsonan nasal medio-palatal terjadi bila penghambat artikulasi aktifnya ialah tengah lidah dan artikulator pasifnya adalah langit-langit keras. Distribusi

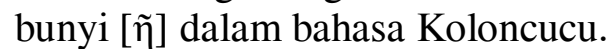
Konsonan awal tengah akhir [ $\tilde{\eta}]$

$$
\begin{array}{lll}
\text { - } & \text { tonyoko } \\
\text { - } & \text { [toñoko] - }
\end{array}
$$

$$
\text { - 'bungkus' - }
$$

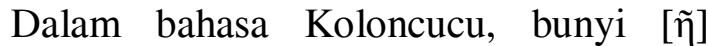
hanya dapat berdistribusi tengah kata sebagai konsonan bersuara, dan tidak dapat berfungsi sebagai awal ataupun penutup kata.

\subsubsection{Konsonan nasal dorso-velar}

Konsonan nasal medio-palatal terjadi bila penghambat artikulasi aktifnya ialah pangkal lidah dan artikulator pasifnya adalah langit-langit lunak. Distribusi bunyi [n] dalam bahasa Koloncucu.

Konsonan awal

$[\mathrm{n}]$

$$
\begin{aligned}
& \text { ngisi[nisi] } \\
& \text { tengah } \\
& \text { anangkamea [anaykamea] } \\
& \text { akhir } \\
& \text { - } \\
& \text { awal } \\
& \text { 'gigi' } \\
& \text { tengah } \\
& \text { 'bayi' } \\
& \text { akhir }
\end{aligned}
$$

Dalam bahasa Koloncucu, bunyi [y] hanya dapat berdistribusi di awal dan tengah kata sebagai konsonan bersuara, dan tidak dapat berfungsi sebagai penutup kata.

\subsubsection{Konsonan Sampingan (Laterals)}

Konsonan sampingan dibentuk dengan menutup arus udara di tengah rongga mulut sehingga udara keluar melalui kedua sampig atau sebuah samping saja. Latera dalam bahasa latin berarti 'samping-samping'. Jadi, strukturnya renggang lebar. Tempat artikulasinya ujung lidah dengan gusi. Bunyi yang dihasilkan disebut samping apikoalveolar. Distribusi bunyi [1] dalam bahasa Koloncucu.

Konsonan awal tengah akhir

[1] lima molawu 'tangan' 'rabun' - 
Bunyi [1] dalam bahasa Koloncucu tidak bisa berdistribusi sebagai penutup kata, keduanya hanya dapat berdistribusi di awal dan tengah sebagai konsonan bersuara.

\subsubsection{Konsonan Geseran atau Frikatif (Fricatives, Fristions)}

Konsonan greseran atau frikatif ialah konsonan yang dibentuk dengan menyempitkan jalannya arus udara yang dihembuskan dengan paru-paru, sehingga jalannya udara terhalang dan keluar bergeser. Jadi, strukturnya tidak dapat seperti konsonan letup tetapi renggang. menurut tempat artikulasinya konsonan geseran dapat dibedakan lagi menjadi sebagai berikut.

\subsubsection{Konsonan geseran labio-dental}

Konsonan geseran labio-dental tejadi bila artikulator aktifnya ialah bibir bawah dan artikulator pasifnya ialah gigi atas. Bunyi yang terjadi ialah $[f, v]$. Perbedaan di antara kedua bunyi geseran itu ialah [f] sebagai konsonan keras tak bersuara, sedangkan [v] adalah kosonan lunak bersuara. Distribusi bunyi [n] dalam bahasa Koloncucu.

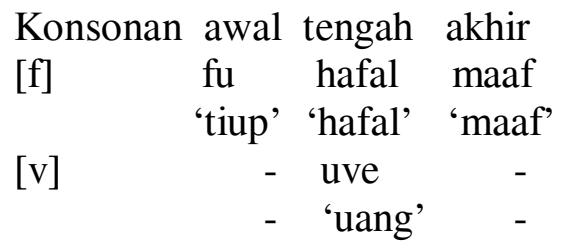

Dalam bahasa Koloncucu, bunyi [f] tidak hanya dapat berdistribusi di awal dan tengah kata sebagai konsonan keras tak bersuara, tetapi juga dapat berfungsi sebagai penutup kata. Sedangkan bunyi [v] hanya dapat berdistribusi di tengah saja.

\subsubsection{Kosonan geseran lamino-alveolar} Kosonan geseran lamino-alveolar tejadi bila artikulator aktifnya ialah daun lidah dan ujung sedangkan artikulator pasifnya ialah gusi. Distribusi bunyi [s] dan [z] dalam bahasa Koloncucu.

$\begin{array}{lllr}\text { Konsonan } & \text { awal } & \text { tengah } & \text { akhir } \\ {[\mathrm{s}]} & \text { sarewu } & \text { pisi } & - \\ & \text { 'seribu' } & \text { 'pijit' } & - \\ {[\mathrm{z}]} & - & \text { azan } & - \\ & - & \text { 'azan' } & -\end{array}$

Dalam bahasa Koloncucu, bunyi [s] hanya dapat berdistribusi di awal dan tengah kata sebagai konsonan keras tak bersuara dan tidak dapat berfungsi sebagai penutup kata. Sedangkan bunyi [z] hanya dapat berdistribusi di tengah saja.

\subsubsection{Konsonan geseran laringal}

Konsonan geseran laringal atau geseran glottal yang terjadi bila artikulatornya adalah sepangan pasangan pita suara. udara yang dihebuskan dalam posisi terbuka. Posisi terbuka ini lebih sempit dari pada posisi glottis terbuka lebar dalam bernafas normal. Distribusi bunyi [h] dalam bahasa Koloncucu.

Konsonan awal tengah akhir

[h] hansule ponahu 'kembali' 'masak' -

\subsubsection{Konsonan Getar (Trills, Vibrants)}

Konsonan getar atau geletar ialah konsonan yang dibentuk dengan menghambat jalannya arus udara yang dihembuskan dari paru-paru secara berulang-ulang dan cepat. Menurut tempat artikulasinya, konsonan getar ini dapat dibedakan menjadi dua, yaitu konsonan getar apiko-alveolar dan konsonan getar uvular. Dalam bahasa Koloncucu hanya ditemukan konsonan getar apiko-alveolar. Distribusi bunyi [r] dalam bahasa Koloncucu.

Konsonan awal tengah akhir

[r]

$$
\text { rongo mewaro - }
$$


3.1.6 Semi vokal

\subsubsection{Semi-vokal bilabial dan labio dental}

Semi-vokal bilabial dan labio dental terjadi bila artikulator aktifnya adalah bibir bawah dan artikulator pasifnya adalah bibir atas, bunyi yang terjadi adalah [w] bilabial. dapat juga bibir bawah bekerjasama dengan gigi atas, yang terjadi adalah [w] labio dental. Distribusi bunyi [w] dalam bahasa Koloncucu.

Konsonan awal tengah akhir [w] wamba daowa molaw 'pintu' 'pesan' 'rabun
3.1.6.2 Semi-vokal medio-palatal

Semi-vokal medio-palatal terjadi bila artikulator aktifnya ialah tengah lidah dan artikulator pasfnya ialah langit-langit keras. bunyi yang terjadi ialah [y]. Distribusi bunyi [y] dalam bahasa Koloncucu.

Konsonan awal tengah akhir [y] yibhone inayo riay 'pantai' 'siapa' 'disini'

Semi-vokal dalam bahasa Koloncucu dapat bedistribusi ke semua posisi, baik awal, tengah dan akhir kata.

\subsection{Bagan Konsonan Bahasa Koloncucu}

Klasifikasi konsonan bahasa Koloncucu dapat digambarkan dalam bagan berikut.

\section{Bagan 1}

Konsonan Bahasa Koloncucu

\begin{tabular}{|c|c|c|c|c|c|c|c|c|c|c|c|c|c|c|c|}
\hline \multirow[b]{2}{*}{$\begin{array}{l}\text { hubun } \\
\text { gan } \\
\text { posisio } \\
\text { nal } \\
\text { antarp } \\
\text { engha } \\
\text { mbat } \\
\text { (strikt } \\
\text { ur) }\end{array}$} & \multirow{2}{*}{$\begin{array}{l}\text { cara } \\
\text { diha } \\
\text { mbat } \\
\text { (cara } \\
\text { artik } \\
\text { ulasi) }\end{array}$} & \multirow[b]{2}{*}{ 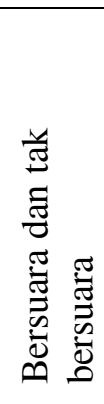 } & \multicolumn{13}{|c|}{ Tempat hambatan } \\
\hline & & & 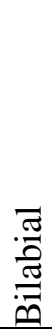 & 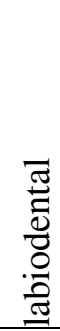 & 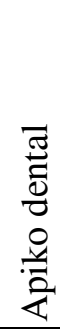 & 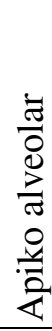 & 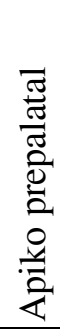 & 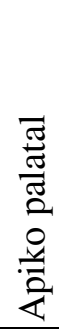 & 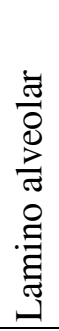 & 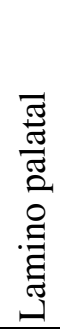 & 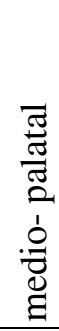 & 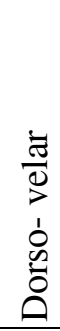 & $\frac{\bar{t}}{3}$ & 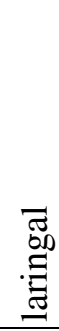 & 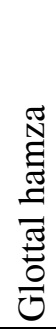 \\
\hline \multirow{2}{*}{$\begin{array}{l}\text { rapat } \\
\text { lepas } \\
\text { tiba- } \\
\text { tiba } \\
\end{array}$} & \multirow{2}{*}{$\begin{array}{l}\text { nasal } \\
\text { (letu } \\
\text { p) }\end{array}$} & $\mathbf{T}$ & $\mathbf{p}$ & & $\mathbf{t}$ & & & & & & c & $\mathbf{k}$ & & & $?$ \\
\hline & & B & $\begin{array}{l}\text { b } \\
\text { bh }\end{array}$ & & $\begin{array}{c}\text { d } \\
\text { dh }\end{array}$ & & & & & & $\mathbf{j}$ & $\mathbf{g}$ & & & \\
\hline $\begin{array}{l}\text { rapat } \\
\text { lepas } \\
\text { tiba- } \\
\text { tiba }\end{array}$ & $\begin{array}{l}\text { nasal } \\
\text { (seng } \\
\text { au) }\end{array}$ & B & $\mathbf{m}$ & & & $\mathbf{n}$ & & & & & $\tilde{\boldsymbol{\eta}}$ & ⿹ & & & \\
\hline \multirow{2}{*}{$\begin{array}{l}\text { rapat } \\
\text { lepas } \\
\text { pelan- } \\
\text { pelan }\end{array}$} & \multirow{2}{*}{$\begin{array}{l}\text { padu } \\
\text { an } \\
\text { afrik } \\
\text { at }\end{array}$} & & & & & & & & & & & & & & \\
\hline & & & & & & & & & & & & & & & \\
\hline $\begin{array}{l}\text { rengga } \\
\text { ng } \\
\text { lebar }\end{array}$ & $\begin{array}{l}\text { samp } \\
\text { ingan } \\
\text { (leter } \\
\text { al) }\end{array}$ & B & & & & 1 & & & & & & & & & \\
\hline \multirow{2}{*}{$\begin{array}{l}\text { rengga } \\
\text { ng }\end{array}$} & \multirow{2}{*}{$\begin{array}{l}\text { geser } \\
\text { an } \\
\text { (frika } \\
\text { tif) }\end{array}$} & $\mathbf{T}$ & & $\mathbf{f}$ & & & & & $\mathbf{s}$ & & & $\mathbf{x}$ & & \multirow[b]{2}{*}{ h } & \\
\hline & & $\mathbf{B}$ & & $\mathbf{v}$ & & & & & $\mathbf{z}$ & & & & & & \\
\hline
\end{tabular}




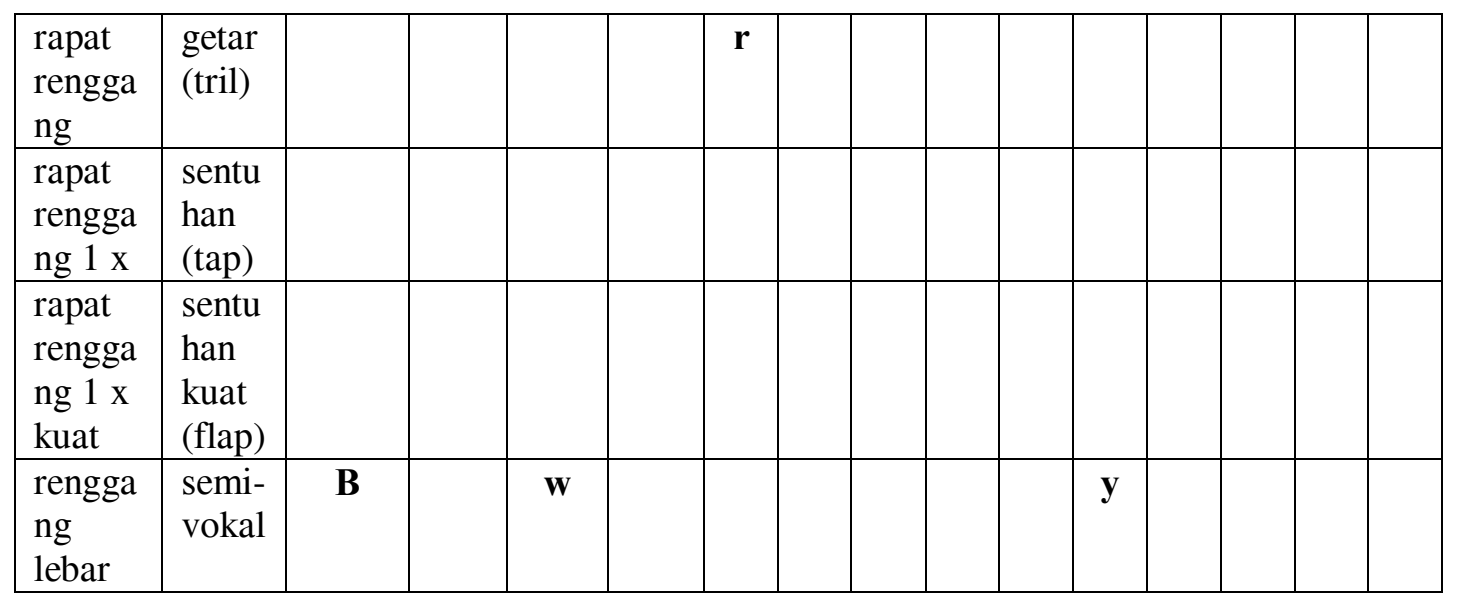

Ket: *) tidak ada dalam bahasa Jawa. $\mathrm{T}=$ Tidak bersuara. $\mathrm{B}=$ bersuara

\section{Penutup}

\subsection{Simpulan}

Hasil tulisan ini adalah bentuk dan klasifikasi konsonan dalam bahasa Koloncucu, yaitu:

1. dari 21 konsonan dalam Bahasa Indonesia, bahasa Koloncucu hanya memiliki 19 konsonan (b, c, d, f, g, $\mathrm{h}, \mathrm{j}, \mathrm{k}, \mathrm{l}, \mathrm{m}, \mathrm{n}, \mathrm{p}, \mathrm{r}, \mathrm{s}, \mathrm{t}, \mathrm{v}, \mathrm{w}, \mathrm{y}, \mathrm{dan}$ z);

2. bentuk dan klasifikasi konsonan bahasa Koloncucu yaitu konsonan hambat letup (Stops, Plosives), konsonan nasal (Nasals), konsonan sampingan (Laterals), konsonan geseran atau frikatif (Fricatives, Fristions), konsonan getar (Trills, Vibrants), dan semi vokal. Sedangkan konsonan sentuhan (Tap), konsonan sentuhan kuat (Flap), dan konsonan paduan (Affricates) tidak ditemukan dalam bahasa Koloncucu;

3. hanya konsonan hamzah dan semivokal yang dapat berdistribusi pada bagian awal, tengah, dan akhir kata. 19 konsonan lainnya hanya dapat berdistribusi di awal dan tengah kata; dan

4. beberapa konsonan tertentu terdapat bunyi aspirasi, misalnya $\left[\mathrm{d}^{\mathrm{h}}\right]$ dan $\left[\mathrm{b}^{\mathrm{h}}\right]$

\subsection{Saran}

Setelah kajian konsonan dalam bahasa Koloncucu, selanjutnya diperlukan kajian gramatika yang lain (fonologi, morfologi dan sintaksis). Penelitian lanjutan yang terstruktur sangat diperlukan sebagai bank data bahasa Koloncucu, referensi bandingan bagi penelitian selanjutnya, dan sebagai bentuk upaya pelestarian bahasa Koloncucu.

\section{Daftar Pustaka}

Alwi, Hasan.et al. 1993. Tata Bahasa Baku Bahasa Indonesia. Jakarta: Balai Pustaka.

Dongoran, Tumpal H. et al. 1997.

Fonologi Bahasa Angkola. Jakarta:

Pusat Pembinaan dan

Pengembangan Bahasa.

Fokaaya, dkk. 2014. Bahasa-bahasa Daerah di Maluku Utara. Ternate: Kantor Bahasa Maluku Utara.

Kenjono, Djoko. 2005. Pesona Bahasa: Langkah Awal Memahami Linguistik. Jakarta: Gramedia Pustaka Utama.

Krauss, Michael. 1992. The World's Languages in crisis. Volume 68, Number I

Kridalaksana, Harimurti. 2007. Kamus Linguistik. Edisi ketiga. Jakarta: Gramedia Pustaka Utama

Mahsun. 2007. Metode Penelitian Bahasa (Tahapan, Strategi, Metode, dan Tekniknya). Jakarta: Raja Grafindo Persada. 
Marsono. 2013. Fonetik. Yogyakarta: Gadjah Mada University Press.

Muhammad. 2012. Metode dan Teknik Analisis Data Linguistik. Yogyakarta: Liebe Book Press.

Pateda, Mansoer. 2001. Semantik Leksikal. Jakarta: Rineka Cipta

Sudaryanto, 1993. Metode dan Aneka Teknik Analisis Bahasa. Yogyakarta: MLI Komsariat Universitas Gajah Mada.

Verhaar, J.W.M. 2010. Asas-asas

Linguistik Umum. Yogyakarta: UGM Press.

Wibowo, Wahyu. 2001. Manajemen Bahasa. Jakarta:Gramedia. 